\section{(2) OPEN ACCESS}

\title{
Lifestyle modification in older versus younger patients with coronary artery disease
}

\author{
Patricia Jepma (D) , 1,2 Harald T Jorstad, ${ }^{1}$ Marjolein Snaterse, ${ }^{2}$ Gerben ter Riet, ${ }^{1,2}$ \\ Hans Kragten, ${ }^{3}$ Sangeeta Lachman, ${ }^{1}$ Madelon Minneboo, ${ }^{1}$ S Matthijs Boekholdt, ${ }^{1}$ \\ Ron J Peters, ${ }^{1}$ Wilma Scholte op Reimer ${ }^{2,3}$
}

- Additional material is

published online only. To view, please visit the journal online (http://dx.doi.org/10.1136/ heartjnl-2019-316056).

'Department of Cardiology, Amsterdam UMC, University of Amsterdam, Amsterdam, The Netherlands

${ }^{2}$ Achieve Centre for Applied Research, Faculty of Health, Amsterdam University of Applied Sciences, Amsterdam, The Netherlands ${ }^{3}$ Cardiology, Zuyderland Medical Centre, Heerlen, The Netherlands

\section{Correspondence to}

Ms Patricia Jepma, Department UMC, University of Amsterdam, Amsterdam, The Netherlands; p.jepma@amsterdamumc.nl

Received 1 October 2019 Revised 10 February 2020 Accepted 10 February 2020 Published Online First 16 March 2020 of Cardiology, Amsterdam

\section{ABSTRACT \\ Objective To compare the treatment effect on} lifestyle-related risk factors (LRFs) in older ( $\geq 65$ years) versus younger ( $<65$ years) patients with coronary artery disease (CAD) in The Randomised Evaluation of Secondary Prevention by Outpatient Nurse SpEcialists 2 (RESPONSE-2) trial.

Methods The RESPONSE-2 trial was a communitybased lifestyle intervention trial $(n=824)$ comparing nurse-coordinated referral with a comprehensive set of three lifestyle interventions (physical activity, weight reduction and/or smoking cessation) to usual care. In the current analysis, our primary outcome was the proportion of patients with improvement at 12 months follow-up $(n=711)$ in $\geq 1$ LRF stratified by age.

Results At baseline, older patients ( $n=245$, mean age $69.2 \pm 3.9$ years) had more adverse cardiovascular risk profiles and comorbidities than younger patients $(n=579$, mean age $53.7 \pm 6.6$ years). There was no significant variation on the treatment effect according to age ( $p$ value treatment by age $=0.45$, OR $1.67,95 \% \mathrm{Cl} 1.22$ to 2.31). However, older patients were more likely to achieve $\geq 5 \%$ weight loss (OR old $5.58,95 \% \mathrm{Cl} 2.77$ to 11.26 vs $\mathrm{OR}$ young $1.57,95 \% \mathrm{Cl} 0.98$ to $2.49, \mathrm{p}=0.003$ ) and younger patients were more likely to show nonimproved LRFs (OR old $0.38,95 \% \mathrm{Cl} 0.22$ to 0.67 vs OR young $0.88,95 \% \mathrm{Cl} 0.61$ to $1.26, \mathrm{p}=0.01)$.

Conclusion Despite more adverse cardiovascular risk profiles and comorbidities among older patients, nursecoordinated referral to a community-based lifestyle intervention was at least as successful in improving LRFs in older as in younger patients. Higher age alone should not be a reason to withhold lifestyle interventions in patients with CAD.

\section{INTRODUCTION}

- http://dx.doi.org/10.1136/ heartjnl-2019-316497

Check for updates

(C) Author(s) (or their employer(s)) 2020. Re-use permitted under CC BY-NC. No commercial re-use. See rights and permissions. Published by BMJ.

To cite: Jepma P, Jorstad HT, Snaterse $\mathrm{M}$, et al. Heart 2020;106:1066-1072.
The prevalence of coronary artery disease (CAD) increases with age, ${ }^{1}$ and due to increasing life expectancies expected to further increase in the coming decades. ${ }^{2}$ Interventions to reduce lifestyle-related risk factors (LRFs) such as overweight, physical inactivity and smoking have proven to be effective in secondary prevention of cardiovascular events and are also recommended in older patients. ${ }^{34}$ However, treatment complexity in older patients is greater, due to polypharmacy, comorbidities and functional decline, which may interfere with secondary prevention. ${ }^{256}$ Therefore, accessible and individualised programmes are needed, particularly in older patients. ${ }^{7}$ However, evidence for the efficacy of various lifestyle prevention programmes in older patients is less conclusive than in younger patients. $^{34}$

The Randomised Evaluation of Secondary Prevention by Outpatient Nurse SpEcialists 2 (RESPONSE-2) trial was a community-based lifestyle intervention trial evaluating nurse-coordinated referral to a comprehensive set of three lifestyle interventions (weight reduction, physical activity and/or smoking cessation). ${ }^{89}$ In the overall population significant improvements were seen in LRFs in the intervention group as compared with usual care. However, it is unclear whether these effects differ according to age. We therefore performed a secondary analysis in the RESPONSE-2 trial comparing the treatment effect on LRFs in older ( $\geq 65$ years) vs younger ( $<65$ years) patients. We hypothesised that the treatment effect on LRFs in the overall RESPONSE-2 population was comparable in older and younger patients.

\section{METHODS \\ Study design}

We used data from the RESPONSE-2 trial $(\mathrm{n}=824)$, a multicentre, randomised controlled trial conducted in 15 hospitals in the Netherlands. ${ }^{8}$ The trial was designed to examine the effect of nurse-coordinated referral to a comprehensive set of up to three community-based interventions to improve LRFs in patients with CAD. Written informed consent was obtained from all patients. The methods and outcomes are described in detail elsewhere ${ }^{89}$ and are briefly summarised below. In the current study, we compared improvements in LRFs at 12 months follow-up in older (65-84 years) versus younger (32-65 years) patients.

\section{Patient population}

In the RESPONSE- 2 trial, patients aged 18 years or older were eligible $<8$ weeks after hospitalisation for acute coronary syndrome (ACS), and/or coronary revascularisation, if they had at least one of the following lifestyle risk factors: (1) body mass index $(\mathrm{BMI}) \geq 27 \mathrm{~kg} / \mathrm{m}^{2}$, (2) self-reported physical inactivity $(<30 \mathrm{~min}$ of physical activity of moderate intensity five times per week), (3) self-reported current smoking or stopped $\leq 6$ months before hospital admission, and if they reported to be motivated to attend at least one lifestyle programme. 
Exclusion criteria were: planned revascularisation after discharge; life expectancy $\leq 2$ years; congestive heart failure New York Heart Association class III or IV; visits to outpatient clinic and/or lifestyle programme not feasible; no internet access and anxiety or depressive symptoms (Hospital Anxiety and Depression Scale (HADS) >14), as this was expected to impede lifestyle changes. ${ }^{10}$

All patients received usual care, including visits to the cardiologist, cardiac rehabilitation according to national and international guidelines ${ }^{311}$ and up to four visits to a nurse-coordinated secondary prevention programme addressing healthy lifestyles, biometric risk factors and medication adherence.

\section{Public and patient involvement}

The RESPONSE-2 trial was based on the evaluation of the RESPONSE-1 trial, including involvement from participating nurses and patients. ${ }^{12} 13$ During the study, patients were filmed for the training of participating nurses and were asked about their experiences with the lifestyle programme(s). The nurses contributed to the development and implementation of the study and spread a leaflet with study results among patients.

\section{Nurse-coordinated care and referral to lifestyle programmes}

Patients in the intervention group were referred to up to three lifestyle programmes by registered nurses with experience in cardiovascular care. The number and sequence of the lifestyle programmes was determined by patient's risk profile/preferences. Nurses were trained in a systematic referral approach, consisting of risk status assessment, discussing the current risk status with patients and assessing levels of motivation to sustain or improve LRFs. Depending on levels of motivation, participation in relevant lifestyle programme(s) was advised, followed by referral.

The three lifestyle programmes (Weight Watchers, Philips DirectLife and Luchtsignaal smoking cessation) were offered in their existing format. In short, the weight loss programme (Weight Watchers) was provided as a programme for weight reduction by addressing diet patterns, unhealthy behaviour and physical activity. Weekly group-based sessions were provided. The physical activity programme (Philips DirectLife) was offered as an internet-based programme with an accelerometer and personalised feedback by an online coach to monitor and improve physical activity. Luchtsignaal provided a telephone counselling-based smoking cessation programme based on motivational interviewing by trained professionals, and pharmacological treatments for smoking cessation were prescribed, as appropriate. More details about the nurse-coordinated care and lifestyle programmes have been described elsewhere. ${ }^{89} 14$

\section{Data collection and measurements}

Data were collected at baseline (first visit within 8 weeks after hospital discharge) and at 12 months, and included cardiovascular history and risk factors, dietary status, physical activity, smoking status and medication use. Body weight, height and waist circumference were measured and BMI was calculated. Physical activity was measured by the $6 \mathrm{~min}$ walking distance (6MWD). ${ }^{15}$ Smoking status was assessed by a urinary cotinine test (UltiMed one step, Dutch Diagnostic, Zutphen, the Netherlands; detection limit $200 \mathrm{ng} / \mathrm{mL}$ ).

\section{Outcomes}

We compared the treatment effect in older (65-84 years) versus younger (32-64 years) patients. The primary outcome was improvement in $\geq 1 \mathrm{LRF}(\mathrm{s})$ without deterioration in the other two LRFs at 12 months follow-up. Improvement was defined as: (1) weight loss of $\geq 5 \%{ }^{11}$; (2) a urine cotinine level $<200 \mathrm{ng} / \mathrm{m}$ and/or 3) $>10 \%$ increase in $6 \mathrm{MWD} .{ }^{16}$ Deterioration was defined as: (1) any weight gain in combination with a BMI $>25 \mathrm{~kg} / \mathrm{m}^{2}$; (2) a positive cotinine test $(>200 \mathrm{ng} / \mathrm{mL})$ in non-smokers at baseline and (3) any decrease in 6MWD compared with baseline. Two exceptions were made: in patients who stopped smoking and/or improved their 6MWD, an increase of $2.5 \%$ in BMI was classified as no deterioration. Secondary outcomes included differences in isolated LRFs (weight, smoking and physical activity) and an LRF analysis of no improvement. We analysed non-improved patients defined as patients with $\geq 1 \mathrm{LRF}(\mathrm{s})$ not on target at baseline and who had remained not on target 12 months later. $^{89}$

\section{Statistical methods}

Continuous variables are described using means with SD for normally distributed data and medians with IQR for nonnormally distributed data. Categorical variables are presented using frequencies and percentages.

The variation in treatment effect by age was first investigated using unadjusted logistic regression analyses (OR with 95\% CI) including treatment, age (dichotomised at 65 years) and an interaction term of treatment by age. We considered $\mathrm{p}$ values $<0.10$ indicative of variation in treatment effect and then reported separate ORs. Statistically non-significant interaction terms $(p \geq 0.10)$ were interpreted as an indication that there was no variation in treatment effect by age. In these outcomes, we reported the OR of the analyses in the overall population (figure 1, table 1).

The baseline measurements of the variables age, sex, marital status, educational level, BMI $\geq 27 \mathrm{~kg} / \mathrm{m}^{2}$, self-reported physical inactivity, self-reported current smoking or stopped $\leq 6$ months before hospital admission, low-density lipoprotein cholesterol, systolic blood pressure, diabetes mellitus and no history of cardiovascular disease (CVD) were identified as potential confounders. Then, we performed adjusted logistic regression analyses to examine if there were any discrepancies between the unadjusted and adjusted regression analyses regarding treatment by age interactions. As a sensitivity analysis, we investigated (in unadjusted analyses) how the treatment effect varied across the whole age spectrum (from 32 to 84 years) with age as a continuous variable, using the non-parametric method as described by Bonetti and Gelber ${ }^{17}$ and the parametric method as described by Royston and Sauerbrei. ${ }^{18} 19$

Statistical analyses were performed using SPSS V.24.0 (IBM, Armonk, New York, USA) and Stata V.13.1 (StataCorp, 2013).

\section{RESULTS}

\section{Patient characteristics}

A total of 824 participants were randomised in the RESPONSE-2 trial. In 711 patients, outcome data were complete and these patients were included in the primary analysis (figure 2). Mean age was $69.2 \pm 3.9$ years in older patients and $53.7 \pm 6.6$ in younger patients (table 2). Overall, 20.4\% of older patients and $22.1 \%$ of younger patients were female. Older patients more frequently had a history of CVD $(45.3 \%$ vs $30.6 \%, \mathrm{p}<0.001)$ and more comorbid conditions, such as hypertension $(52.5 \%$ vs $34.2 \%, \mathrm{p}<0.001)$, diabetes mellitus $(24.1 \%$ vs $11.9 \%, \mathrm{p}<0.001)$ and peripheral artery disease $(9.8 \%$ vs $2.6 \%, \mathrm{p}<0.001)$ compared with younger patients (tables 2 and 3 ). There were no significant differences in medication prescriptions between older and younger patients at baseline. 
Outcomes

Success on $\geq 1 \operatorname{LRF}(\mathrm{s})$

No improvement

Physical activity
Weight reduction

\section{ז9}

.

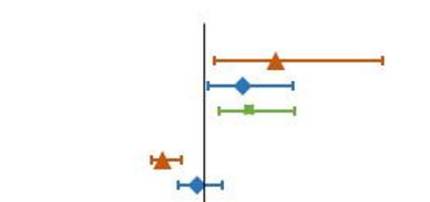

Smoking cessation

Physical activity

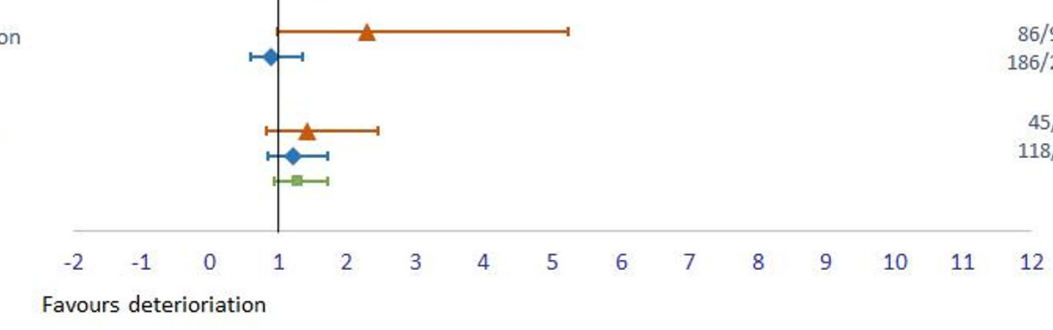

Intervention vs. Control OR $(95 \% \mathrm{Cl})$

$41 / 99$ vs. $31 / 120,2.03(1.15-3.60)$

$92 / 261$ vs. $60 / 231,1.55(1.05-2.29)$

$1.67(1.22-2.31)$

$37 / 99$ vs. $73 / 120,0.38(0.22-0.67)$

$108 / 261$ vs. $103 / 231,0.88(0.61-1.26)$

$40 / 99$ vs. $13 / 120,5.58(2.77-11.26)$

$56 / 261$ vs. $35 / 231,1.57(0.98-2.49)$

$86 / 99$ vs. $95 / 120,2.28(0.99-5.24)$

$86 / 261$ vs. $163 / 231,0.90(0.60-1.34)$

$45 / 98$ vs. $45 / 120,1.42(0.82-2.44)$

$118 / 261$ vs. $94 / 231,1.20(0.84-1.72)$

$1.27(0.94-1.71)$

P-value

treatment by age

0.45

0.01

0.003

0.003

0.05

0.62

$\Delta$ Old (65-84 years)

- Young (32-64 years)

- Overall population

Figure 1 Outcomes in lifestyle-related risk factors after 12 months.

Overall, 86.9\% was overweight (BMI $\geq 25 \mathrm{~kg} / \mathrm{m}^{2}$ ) and $63.3 \%$ did not meet the target for adequate physical activity ( $\geq 5$ times per week $30 \mathrm{~min} /$ day moderate physical activity) at baseline (table 3). Younger patients were more often current smokers $(26.1 \%$ vs $14.7 \%, \mathrm{p}<0.001)$ and more frequently had quit smoking within 6 months before or during hospital admission $(31.6 \%$ vs $14.3 \%, \mathrm{p}<0.001)$ than older patients. Both older and younger patients chose most frequently to attend a single lifestyle programme $(50.5 \%$ vs $47.5 \%, \mathrm{p}=0.64)$, of whom $52.0 \%$ and $48.4 \%$ participated in the physical activity programme (online supplementary table S1).

\section{Treatment effect in older and younger patients}

In older patients, $41.4 \%$ patients (41/99) in the intervention group compared with $25.8 \%$ patients $(31 / 120)$ in the control group were successful in improving $\geq 1$ LRFs at 12 months without deterioration in the other LRFs (ie, the primary outcome, table 1$)$. In younger patients, $35.2 \%$ patients $(92 / 261)$ in the intervention group compared with $26.0 \%$ patients (60/231) in the control group improved $\geq 1$ LRFs. In the univariable analyses, older patients in the intervention group were numerically more successful in improving LRFs, however, no variation in treatment effect by age was found $(\mathrm{p}=0.45$, OR overall 1.67 , 95\% CI 1.22 to 2.31 ) (figure 1 ).

Older patients were less likely to show non-improved LRFs at all (interventions: $37.4 \%$ vs controls: $60.8 \%$ ) compared with younger patients (interventions: $41.4 \%$ vs controls: $44.6 \%$ ) (table 1). Furthermore, older patients in the intervention group (OR 0.38 , 95\% CI 0.22 to 0.67 ) were less likely to have nonimproved LRFs as compared with younger patients in the intervention group (OR $0.88,95 \%$ CI 0.61 to 1.26 ) ( $\mathrm{p}$ value treatment by age $=0.01$ ) (figure 1 ).

Older patients were more successful in achieving weight reduction of $\geq 5 \%$ ( $40.4 \%$ interventions vs $10.8 \%$ controls, OR $5.58,95 \%$ CI 2.77 to 11.26 ) compared with younger patients (21.8\% interventions vs $15.2 \%$ controls, OR $1.57,95 \%$ CI 0.98

Table 1 Primary and secondary outcomes

\begin{tabular}{|c|c|c|c|c|c|c|c|}
\hline & \multicolumn{2}{|c|}{ Age $\geq 65$ years } & \multicolumn{2}{|l|}{ Age $<65$ years } & \multirow{2}{*}{$\begin{array}{l}\text { Age } \geq 65 \text { years } \\
\text { OR }(95 \% \mathrm{Cl})\end{array}$} & \multirow{2}{*}{$\begin{array}{l}\text { Age }<65 \text { years } \\
\text { OR }(95 \% \mathrm{Cl})\end{array}$} & \multirow{2}{*}{$\begin{array}{l}\text { Treatment } \\
\text { by age } \\
\text { P value }\end{array}$} \\
\hline & Intervention & Control & Intervention & Control & & & \\
\hline \multicolumn{8}{|l|}{ Primary outcome, $n(\%)$} \\
\hline \multicolumn{8}{|l|}{ Secondary outcomes, n (\%) } \\
\hline No improvement & $37 / 99(37.4)$ & $73 / 120(60.8)$ & $108 / 261(41.4)$ & 103/231 (44.6) & $0.38(0.22$ to 0.67$)$ & $0.88(0.61$ to 1.26$)$ & 0.01 \\
\hline $\begin{array}{l}\geq 5 \% \text { weight reduction in patients with } \\
\text { baseline } \mathrm{BMI} \geq 27 \mathrm{~kg} / \mathrm{m}^{2}\end{array}$ & $38 / 72(52.8)$ & $12 / 87(13.8)$ & $50 / 197(25.4)$ & $27 / 166(16.3)$ & 6.99 (3.25 to 15.01$)$ & 1.75 (1.04 to 2.95$)$ & 0.003 \\
\hline \multicolumn{8}{|l|}{ Smoking status, n (\%) } \\
\hline Urine cotinine $<200 \mathrm{ng} / \mathrm{mL}$ & $86 / 99(86.9)$ & $95 / 120(79.2)$ & $186 / 261(71.3)$ & $163 / 231(70.6)$ & 2.28 (0.99 to 5.24$)$ & 0.90 (0.60 to 1.34$)$ & 0.05 \\
\hline $\begin{array}{l}\text { Urine cotinine }<200 \mathrm{ng} / \mathrm{mL} \text { in smokers }<6 \\
\text { months before admission }\end{array}$ & $17 / 29(58.6)$ & 10/34 (29.4) & $69 / 143(48.3)$ & $66 / 132(50.0)$ & 3.40 (1.20 to 9.66$)$ & 0.93 (0.58 to 1.50$)$ & 0.03 \\
\hline
\end{tabular}




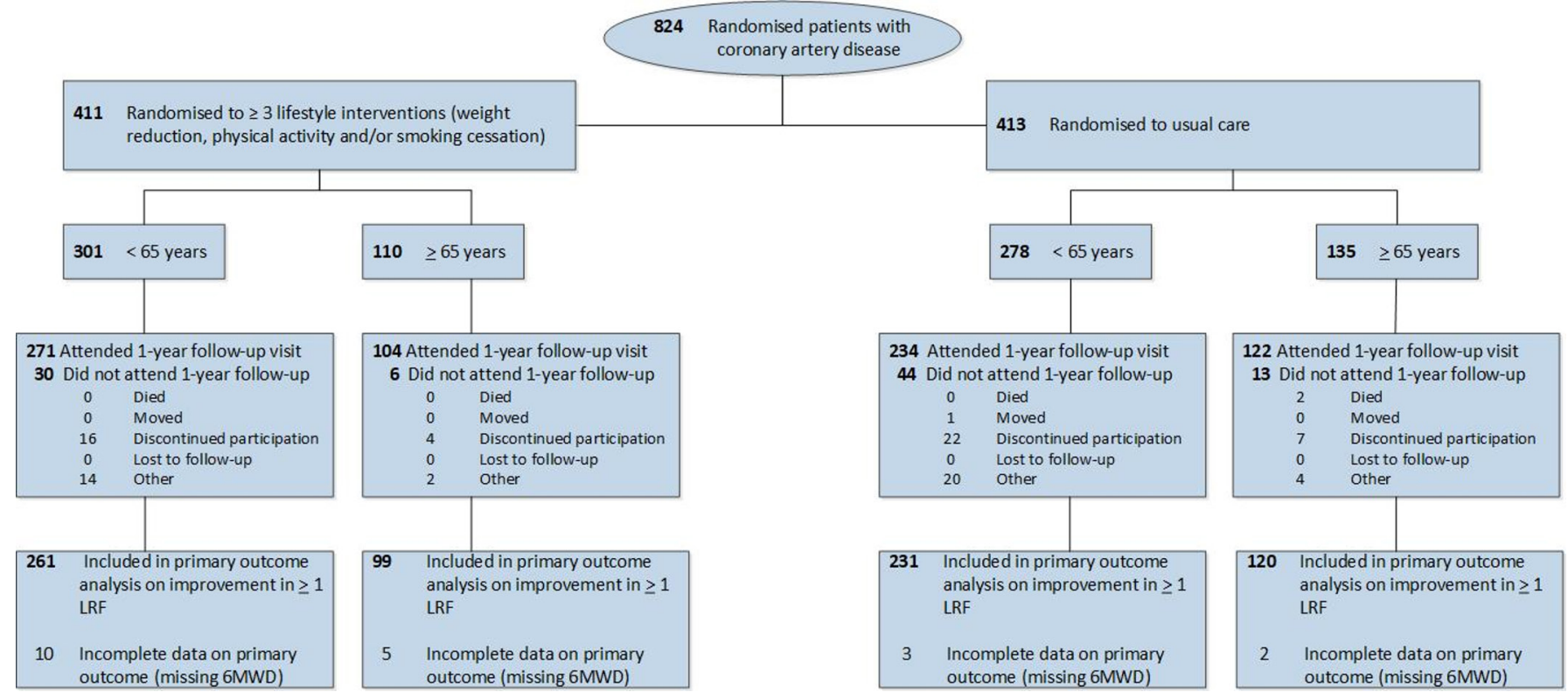

Figure 2 Study population flow chart. 6MWD, 6 min walking distance; LRF, lifestyle-related risk factor.

to 2.49 ) (p value treatment by age $=0.003$ ) (table 1 , figure 1 ). In addition, in patients with a BMI $\geq 27 \mathrm{~kg} / \mathrm{m}^{2}$ at baseline, higher rates of $\geq 5 \%$ weight reduction were observed in older patients (52.8\% interventions vs $13.8 \%$ controls, OR 6.99, 95\% CI 3.25 to 15.01$)$ as compared with younger patients $(25.4 \%$ interventions vs 16.3 controls, OR $1.75,95 \%$ CI 1.04 to 2.95 ) (p value treatment by age $=0.003$ ) (table 1 ). Older patients attended more sessions in the weight reduction programme compared with younger patients (median 30 vs 10, p<0.001) (online supplementary table S1). In patients attending $>30$ sessions, $91.3 \%$ of older patients and $57.9 \%$ of younger patients achieved $\geq 5 \%$ weight reduction $(\mathrm{p}=0.03)$.

Numerically, more older patients had negative cotinine tests (interventions: $86.9 \%$ vs controls: $79.2 \%$, OR 2.28, 95\% CI 0.99 to 5.24 ) compared with younger patients (interventions: $71.3 \%$ vs controls: $70.6 \%$, OR $0.90,95 \%$ CI 0.60 to 1.34 ) (p value treatment by age $=0.05$ ) (table 1 , figure 1 ). In addition, more older pre-event smokers in the intervention quit smoking at 12 months follow-up (58.6\% interventions vs $29.4 \%$ controls, OR $3.40,95 \%$ CI 1.20 to 9.66 ) while in younger smokers no difference was found in smoking cessation rates $(48.3 \%$ interventions vs $50.0 \%$ controls, OR 0.93 , 95\% CI 0.58 to 1.50 ) (p value treatment by age $=0.03$ ) (table 1$)$.

No differences were observed on improvement on the 6MWD in both older (interventions: $45.9 \%$ vs controls: $37.5 \%$ ) and younger patients (interventions: $45.2 \%$ vs controls: $40.7 \%)$ ( $p$ value treatment by age $=0.62$, overall OR $1.27,95 \%$ CI 0.94 to 1.71) (table 1, figure 1).

We did not find any discrepancies between the non-adjusted and adjusted regression analyses regarding the treatment by age interactions.

\section{Sensitivity analysis}

When age was analysed as a continuous variable (online supplementary figures S1-S5), we found that the treatment effect increased with age for the outcomes non-improved LRFs ( $\mathrm{p}$ values ranging from 0.05 to 0.13 ), weight reduction ( $\mathrm{p}$ values ranging from 0.001 to 0.005 ) and smoking cessation ( $\mathrm{p}$ values ranging from 0.03 to 0.94 ). There were no strong indications that treatment effects varied by age for successful improvement on LRFs ( $\mathrm{p}$ values ranging from 0.07 to 0.15 ) and physical activity ( $\mathrm{p}$ values ranging from 0.23 to 0.28 ).

\section{DISCUSSION}

Our findings suggest that despite more adverse cardiovascular risk profiles and comorbidities, nurse-coordinated referral to a community-based lifestyle intervention was at least as successful in improving LRFs in older compared with younger patients. While levels of physical activity did not improve in both groups, older patients in the intervention group were more successful in weight reduction and smoking cessation as compared with younger patients.

At baseline, older patients more frequently had a history of CVD, adverse cardiovascular risk profiles and more comorbidities such as hypertension, diabetes mellitus and peripheral artery disease. In older patients, the risk of recurrent events is higher due to age alone, but comorbidities and risk factors not on target can further increase this risk. ${ }^{320}$ Despite these higher risks, older patients are under-represented in clinical trials, resulting in poor generalisability of interventions in this population. ${ }^{6}$ Our study shows that suboptimal risk profiles in older patients can be modified by easily accessible and widely available community-based prevention programmes. Conversely, success rates in the control groups at 12 months were identical for the two age groups. A considerable percentage of older patients in the control group (61\%) showed no improvement in LRFs, demonstrating that risk modification in older patients is suboptimal in the context of usual secondary preventive care, but can be facilitated using lifestyle prevention programmes. However, we observed comparable non-improved LRFs at 12 months follow-up in younger patients in both study groups (intervention $41.4 \%$ vs control $44.6 \%, p=0.47)$. This suggests that both younger and older patients are in need for other lifestyle interventions. Further research is needed to evaluate how secondary preventive care could be customised in this population as younger patients will commonly have many years of being at increased risk of subsequent events. The weight reduction component was the most effective intervention in the overall RESPONSE- 2 trial. ${ }^{8}$ In our age-specific analysis, older patients in the intervention group were more successful in weight reduction than younger patients. 
Table 2 Baseline characteristics

\begin{tabular}{|c|c|c|c|}
\hline & \multirow{2}{*}{$\frac{\text { Age } \geq 65 \text { years }}{(n=245)}$} & \multirow{2}{*}{$\begin{array}{l}\text { Age }<65 \text { years } \\
(n=579)\end{array}$} & \multirow[t]{2}{*}{$P$ value } \\
\hline & & & \\
\hline \multicolumn{4}{|l|}{ Demographics and medical history } \\
\hline Age, years & $69.2 \pm 3.9$ & $53.7 \pm 6.6$ & $<0.001$ \\
\hline Female & $50(20.4)$ & $128(22.1)$ & 0.59 \\
\hline Caucasian & $234(95.5)$ & $529(91.4)^{*}$ & 0.04 \\
\hline Higher education (>13 years) & $95(38.8)$ & $236(40.8)$ & 0.64 \\
\hline $\begin{array}{l}\text { Relationship (married or } \\
\text { cohabiting) }\end{array}$ & $198(80.8)$ & $471(81.3)$ & 0.85 \\
\hline \multicolumn{4}{|l|}{ Index event } \\
\hline $\begin{array}{l}\text { ST-segment elevation myocardial } \\
\text { infarction }\end{array}$ & $77(31.4)$ & $266(45.9)$ & $<0.001$ \\
\hline $\begin{array}{l}\text { Non-ST-segment elevation } \\
\text { myocardial infarction }\end{array}$ & $91(37.1)$ & $200(34.5)$ & 0.47 \\
\hline Unstable angina & $28(11.4)$ & $40(6.9)$ & 0.04 \\
\hline $\begin{array}{l}\text { Stable angina requiring } \\
\text { revascularisation }\end{array}$ & $49(20.0)$ & $73(12.6)$ & 0.01 \\
\hline \multicolumn{4}{|l|}{ Treatment } \\
\hline $\begin{array}{l}\text { Percutaneous coronary } \\
\text { intervention }\end{array}$ & $180(73.5)$ & $459(79.3)$ & 0.08 \\
\hline Coronary artery bypass surgery & $35(14.3)$ & $52(9.0)$ & 0.03 \\
\hline Medication only & $30(12.2)$ & $68(11.7)^{*}$ & 0.82 \\
\hline \multicolumn{4}{|l|}{ Medication prescription } \\
\hline $\begin{array}{l}\text { Antiplatelet/anticoagulation } \\
\text { agents }\end{array}$ & $244(99.6)$ & $578(99.8)$ & 0.51 \\
\hline Beta-blockers & $209(85.3)$ & $493(85.1)$ & 1.00 \\
\hline ACE inhibiter/ARB & $190(77.6)$ & $423(73.1)$ & 0.19 \\
\hline Lipid-lowering drugs & $239(97.6)$ & $559(96.5)$ & 0.52 \\
\hline \multicolumn{4}{|l|}{ Previous cardiovascular disease } \\
\hline Myocardial infarction & $62(25.3)$ & $121(20.9)$ & 0.17 \\
\hline $\begin{array}{l}\text { Percutaneous coronary } \\
\text { intervention }\end{array}$ & $49(20.0)$ & 79 (13.6) & 0.03 \\
\hline Coronary artery bypass surgery & $19(7.8)$ & $12(2.1)$ & $<0.001$ \\
\hline Stroke & $12(4.9)$ & $14(2.4)$ & 0.08 \\
\hline Peripheral artery disease & $24(9.8)$ & $15(2.6)$ & $<0.001$ \\
\hline $\begin{array}{l}\text { No known history of cardiovascular } \\
\text { disease }\end{array}$ & $134(54.7)^{*}$ & $402(69.4)$ & $<0.001$ \\
\hline
\end{tabular}

Values are mean \pm SD or $\mathrm{n}(\%)$.

${ }^{*}$ Difference between intervention and control group after randomisation, $\mathrm{p}<0.05$. ARB, angiotensin II receptor blockers.

This might be explained by the higher attendance rate of older patients to the weight reduction programme. Our findings are in line with previous reports that identified older age as an important determinant for dietary adherence in lifestyle modification programmes. ${ }^{21}{ }^{22}$ Although long-term effects of weight reduction on mortality in older adults remain to be established, weight loss has shown to be associated with increased functional independence and higher quality of life, ${ }^{23}{ }^{24}$ both important outcomes for older patients. ${ }^{4}$ However, caution is required in older patients with unintended weight loss as it can be a sign of underlying pathology or deconditioning. 2526

Previous research has shown that older patients are more successful in smoking cessation if they have recently been hospitalised for an ACS or revascularisation, ${ }^{27}$ have previously experienced multiple cardiac events or procedures ${ }^{28}$ or associate health-related complaints with smoking. ${ }^{29}{ }^{30}$ This is in line with our findings, as we found more successful quitters among the older patients in the intervention group as compared with younger patients, and older patients more frequently had a history of CVD and more comorbidities. Interestingly, only 7/29
Table 3 Risk profiles and lifestyle-related risk factors at baseline

\begin{tabular}{|c|c|c|c|}
\hline & $\begin{array}{l}\text { Age } \geq 65 \text { years } \\
(n=245)\end{array}$ & $\begin{array}{l}\text { Age }<65 \text { years } \\
(\mathrm{n}=579)\end{array}$ & $P$ value \\
\hline \multicolumn{4}{|l|}{ Risk profiles } \\
\hline $\mathrm{BMI}$, mean (SD), $\mathrm{kg} / \mathrm{m}^{2}$ & $29.9 \pm 4.6$ & $29.6 \pm 4.4$ & 0.35 \\
\hline Overweight (BMI $\geq 25 \mathrm{~kg} / \mathrm{m}^{2}$ ) & $16(88.2)$ & $500(86.4)$ & 0.57 \\
\hline Overweight (BMI $\geq 27 \mathrm{~kg} / \mathrm{m}^{2}$ ) & $182(74.3)$ & $427(73.7)$ & 0.93 \\
\hline $\begin{array}{l}\text { Quit smoking } \leq 6 \text { months } \\
\text { (baseline) }\end{array}$ & $35(14.3)$ & $183(31.6)$ & $<0.001$ \\
\hline Physically inactive & $158(64.5)$ & $364(62.9)$ & 0.69 \\
\hline $\begin{array}{l}\text { Systolic blood pressure } \\
\geq 140 \mathrm{~mm} \mathrm{Hg}\end{array}$ & $124(50.6)$ & $171(29.5)$ & $<0.001$ \\
\hline $\mathrm{LDL}$ cholesterol $\geq 1.8 \mathrm{mmol} / \mathrm{L}$ & $155(63.3)$ & $408(70.5)$ & 0.02 \\
\hline Waist circumference, $\mathrm{cm}$ & $108.5 \pm 12.1^{*}$ & $106.0 \pm 11.9^{*}$ & 0.01 \\
\hline 6MWD, m & $433 \pm 103$ & $506 \pm 107$ & $<0.001$ \\
\hline History of hypertension & $128(52.5)$ & $198(34.2)^{*}$ & $<0.001$ \\
\hline History of diabetes mellitus & $59(24.1)$ & $69(11.9)$ & $<0.001$ \\
\hline History of dyslipidaemia & $69(28.2)$ & $115(19.9)$ & 0.01 \\
\hline \multicolumn{4}{|c|}{ Eligibility for lifestyle programmes, n (\%) } \\
\hline Eligible WeightWatchers & $182(74.3)$ & $427(73.7)$ & 0.93 \\
\hline Eligible Luchtsignaal & $71(29.0)$ & $334(57.7)$ & $<0.001$ \\
\hline Eligible DirectLife & $158(64.5)$ & $364(62.9)$ & 0.69 \\
\hline
\end{tabular}

Values are mean $\pm \mathrm{SD}$ or $\mathrm{n}(\%)$.

*Difference between intervention and control group after randomisation, $p<0.05$. BMI, body mass index; LDL, low-density lipoprotein; 6MWD, 6 min walking distance.

(24.1\%) of the eligible older patients in the intervention group attended the smoking cessation programme (online supplementary table S1). Presumably, the longer duration of smoking in patients at higher age contributes to the difficulties in quitting. We have previously shown that patients who quit smoking immediately during or directly after hospital admission are more successful in long-term smoking abstinence. ${ }^{14} 31$ Therefore, healthcare providers should use the opportunity of hospitalisation to discuss smoking cessation with patients.

In the RESPONSE- 2 trial, the attendance rates to the physical activity and smoking cessation programmes were comparable between older and younger patients, except for the weight reduction programme, which was more frequently visited by older patients. Retirement has been shown to be associated with successful lifestyle modification, presumably because retired adults have more time to implement lifestyle changes in their daily life. ${ }^{32}$ In addition, the nurse-coordinated lifestyle programmes in the RESPONSE- 2 trial were community-based and easily accessible, potentially removing barriers which normally might have contributed to non-participation.

\section{Strengths and limitations}

There are several strengths to our study. First, we examined the effect of a large multicentre randomised trial on lifestyle modification in older patients. Second, the community-based lifestyle interventions were uniformly offered in their existing format which facilitates implementation in daily practice for older as well as for younger patients. Third, all lifestyle outcomes were objectively measured.

Some aspects our study warrant consideration. First, our study population included a relatively healthy group of older patients. Patients were eligible if they were able to visit the outpatient clinic and lifestyle programmes and had little no anxiety or depression disorders (HADS $\leq 14$ ). Therefore, our findings cannot readily be extrapolated to older and sicker patients with multimorbid conditions and a high level of frailty. Such patients 
might benefit more from cardiac rehabilitation programmes or functional interventions rather than lifestyle modification aimed at long-term secondary prevention.

Second, assessing effect modification by age after dichotomising age at 65 years can be attractive from a clinical decisionmaking perspective. To some extent the cut-off is arbitrary, as other cut-offs may also be considered. The current cut-off of 65 years was based on the current European guidelines that still use 65 years as a cut-off point for older patients ${ }^{3}$ in combination with the limited sample of patients aged $>70$ years in our study. However, a dichotomised cut-off point can be problematic as it entails some statistical inefficiency. In addition, it is biologically implausible that a sudden change in effect exists at the age of 65 years. Therefore, to supplement our main analysis we performed extensive parametric and non-parametric analyses using age as a continuous variable, which supported our finding that the treatment effect was at least of the same magnitude in older as in younger patients.

\section{CONCLUSION}

Despite the higher prevalence of risk factors and comorbidities, nurse-coordinated referral to a community-based lifestyle intervention appears to be at least as successful in improving lifestyle in older as in younger patients. These results suggest that age alone should not be a reason to withhold lifestyle interventions in older patients with CAD.

\section{Key questions}

\section{What is already known on this subject?}

- Lifestyle interventions are recommended for patients with coronary artery disease (CAD), however the evidence of the effects of lifestyle intervention programmes in older patients is less conclusive than in younger patients.

\section{What might this study add?}

- We performed a secondary analysis in The Randomised Evaluation of Secondary Prevention by Outpatient Nurse SpEcialists 2 randomised trial evaluating nurse-coordinated referral to a comprehensive set of three lifestyle interventions (weight reduction, smoking cessation and/or physical activity).

- While older patients had a more adverse cardiovascular risk profile and more comorbidities at baseline, nurse-coordinated referral to a community-based lifestyle intervention was at least as successful in improving lifestyle in older as in younger patients at 12 months follow-up.

\section{How might this impact on clinical practice?}

- Risk factor modification in older patients is suboptimal in the context of usual secondary preventive care, but can be facilitated using easily accessible community-based lifestyle prevention programmes.

- Our results demonstrate that higher age alone should not be a reason to withhold lifestyle interventions in patients with CAD.

\section{Twitter Patricia Jepma @Patricia_Jepma}

Acknowledgements The authors would like to thank the participants in the RESPONSE-2 trial and the contribution of all research nurses (C. de Jong, A. van Dullemen, W. van der Poel, J. Doornenbal, M. Smit, B. van der Linden, S. Tanovic, N. Tenbult-van Limpt, M. Leguit, E. Dijkstra, J. Fischer, H. Saarloos, H. van Lint, H. Groeneweg, I. Kremer, C. Coenjaerds, K. Lansink, A. van Goor, E. J. Wolf, E. de Haan,
M. van Dijkhuizen, A. Meissner, M. van Steenbergen, Z. Aukema-Wouda, I. Sterk, M. Damen-de Vries, M. Zootjes-Mes, T. Eltink, W. Glas, A. Obbema, A. Reijenga and E. de Jong). The authors would also like to thank the management team, research nurses, interviewers, research assistants and other staff who have taken part in the execution of this study.

Contributors PJ had full access to all the study data and takes responsibility for the integrity of the data and the accuracy of the data analysis. Study concept and design (of this secondary analysis): PJ, HTJ, MS, GtR, RJP, WSoR. Acquisition of data: PJ, HTJ, MS, GtR. Analysis and interpretation of data: PJ, HTJ, GtR. Drafting of manuscript: PJ, HTJ, GtR. Critical revision of manuscript: MS, JK, SL, MM, SMB, RJP, WSoR. Statistical analysis: PJ, HTJ, GtR.

Funding The RESPONSE-2 trial was sponsored by WW International Inc. (formally Weight Watchers International, Inc.) (New York, New York, USA), Philips Consumer Lifestyle (Amsterdam and Eindhoven, The Netherlands) and an anonymous private fund (Amsterdam, The Netherlands). This work was also supported by the Netherlands Organisation for Scientific Research (NWO) (grant number 023.009.036) to PJ.

Disclaimer The sponsors had no role in the design, data collection, data analysis, data interpretation and writing of the manuscript.

Competing interests SMB has received personal fees from Pfizer. RJP has received personal fees from Sanofi, Boehringer Ingelheim, Amgen and AstraZeneca.

Patient and public involvement Patients and/or the public were involved in the design, conduct, reporting or dissemination plans of this research. Refer to the 'Methods' section for further details.

Patient consent for publication Not required.

Ethics approval The institutional review boards of all recruiting hospitals approved the study.

Provenance and peer review Not commissioned; externally peer reviewed.

Data availability statement All data relevant to the study are included in the article or uploaded as supplementary information. Requests for analyses of deidentified data from this trial should be directed to: P. Jepma (p.jepma@hva.nl).

Open access This is an open access article distributed in accordance with the Creative Commons Attribution Non Commercial (CC BY-NC 4.0) license, which permits others to distribute, remix, adapt, build upon this work non-commercially, and license their derivative works on different terms, provided the original work is properly cited, appropriate credit is given, any changes made indicated, and the use is non-commercial. See: http://creativecommons.org/licenses/by-nc/4.0/.

\section{ORCID iD}

Patricia Jepma http://orcid.org/0000-0003-1271-6869

\section{REFERENCES}

1 Benjamin EJ, Virani SS, Callaway CW, et al. Heart disease and stroke Statistics-2018 update: a report from the American heart association. Circulation 2018;137:e67-492

2 Bell SP, Orr NM, Dodson JA, et al. What to expect from the evolving field of geriatric cardiology. J Am Coll Cardiol 2015;66:1286-99.

3 Piepoli MF, Hoes AW, Agewall S, et al. 2016 European Guidelines on cardiovascular disease prevention in clinical practice: The Sixth Joint Task Force of the European Society of Cardiology and Other Societies on Cardiovascular Disease Prevention in Clinical Practice (constituted by representatives of 10 societies and by invited experts)Developed with the special contribution of the European Association for Cardiovascular Prevention \& Rehabilitation (EACPR). Eur Heart J 2016;37:2315-81.

4 Fleg JL, Forman DE, Berra K, et al. Secondary prevention of atherosclerotic cardiovascular disease in older adults: a scientific statement from the American heart association. Circulation 2013;128:2422-46.

5 Salim Al-Damluji M, Dzara K, Hodshon B, et al. Association of discharge summary quality with readmission risk for patients hospitalized with heart failure exacerbation. Circ Cardiovasc Qual Outcomes 2015;8:109-11.

6 Rich MW, Chyun DA, Skolnick AH, et al. Knowledge gaps in cardiovascular care of the older adult population: a scientific statement from the American heart association, American College of cardiology, and American geriatrics Society. Circulation 2016;133:2103-22.

7 Wood DA, Kotseva K, Connolly S, et al. Nurse-coordinated multidisciplinary, familybased cardiovascular disease prevention programme (EUROACTION) for patients with coronary heart disease and asymptomatic individuals at high risk of cardiovascular disease: a paired, cluster-randomised controlled trial. Lancet 2008;371:1999-2012.

8 Minneboo M, Lachman S, Snaterse M, et al. Community-Based lifestyle intervention in patients with coronary artery disease: the RESPONSE-2 trial. J Am Coll Cardiol 2017;70:318-27.

9 Lachman S, Minneboo M, Snaterse M, et al. Community-Based comprehensive lifestyle programs in patients with coronary artery disease: objectives, design and 
expected results of randomized evaluation of secondary prevention by outpatient nurse specialists 2 trial (response 2). Am Heart J 2015;170:216-22.

10 Thorndike AN, Regan S, McKool K, et al. Depressive symptoms and smoking cessation after hospitalization for cardiovascular disease. Arch Intern Med 2008; 168:186-91.

11 Smith SC, Benjamin EJ, Bonow RO, et al. AHA/ACCF secondary prevention and risk reduction therapy for patients with coronary and other atherosclerotic vascular disease: 2011 update: a guideline from the American heart association and American College of cardiology Foundation. Circulation 2011;124:2458-73.

12 Jorstad HT, Chan YK, Scholte op Reimer WJM, et al. Nurses' perspectives on nursecoordinated prevention programmes in secondary prevention of cardiovascular disease: a pilot survey. Contemp Nurse 2015;51:96-106.

13 Jorstad HT, von Birgelen C, Alings AMW, et al. Effect of a nurse-coordinated prevention programme on cardiovascular risk after an acute coronary syndrome: main results of the response randomised trial. Heart 2013;99:1421-30.

14 Snaterse M, Jorstad HT, Minneboo M, et al. Smoking cessation after nursecoordinated referral to a comprehensive lifestyle programme in patients with coronary artery disease: a substudy of the RESPONSE- 2 trial. Eur I Cardiovasc Nurs 2019;18:113-21.

15 Bellet RN, Adams L, Morris NR. The 6-minute walk test in outpatient cardiac rehabilitation: validity, reliability and responsiveness--a systematic review. Physiotherapy 2012;98:277-86.

16 Bellet RN, Francis RL, Jacob JS, et al. Repeated six-minute walk tests for outcome measurement and exercise prescription in outpatient cardiac rehabilitation: a longitudinal study. Arch Phys Med Rehabil 2011;92:1388-94.

17 Bonetti M, Gelber RD. Patterns of treatment effects in subsets of patients in clinical trials. Biostatistics 2004;5:465-81.

18 Royston P, Sauerbrei W. Two techniques for investigating interactions between treatment and continuous covariates in clinical trials. Stata J 2009;9:230-51.

19 Royston P, Sauerbrei W. A new measure of prognostic separation in survival data. Stat Med 2004;23:723-48.
20 Verweij L, Peters RJG, Scholte Op Reimer WJM, et al. Validation of the Systematic COronary Risk Evaluation - Older Persons (SCORE-OP) in the EPIC-Norfolk prospective population study. Int J Cardiol 2019;293:226-30.

21 Leung AWY, Chan RSM, Sea MMM, et al. An overview of factors associated with adherence to lifestyle modification programs for weight management in adults. Int $\mathrm{J}$ Environ Res Public Health 2017;14:922.

22 Burgess E, Hassmén P, Pumpa KL. Determinants of adherence to lifestyle intervention in adults with obesity: a systematic review. Clin Obes 2017;7:123-35.

23 Bales CW, Porter Starr KN. Obesity interventions for older adults: diet as a determinant of physical function. Adv Nutr 2018:9:151-9.

24 Gill LE, Bartels SJ, Batsis JA. Weight management in older adults. Curr Obes Rep 2015:4:379-88.

25 Wang S, Ren J. Obesity paradox in aging: from prevalence to pathophysiology. Prog Cardiovasc Dis 2018;61:182-9.

26 Elagizi A, Kachur S, Lavie CJ, et al. An overview and update on obesity and the obesity paradox in cardiovascular diseases. Prog Cardiovasc Dis 2018;61:142-50.

27 Snaterse M, Deckers JW, Lenzen MJ, et al. Smoking cessation in European patients with coronary heart disease. results from the EUROASPIRE IV survey: a registry from the European Society of cardiology. Int J Cardiol 2018;258:1-6.

28 McKenna K, Higgins H. Factors influencing smoking cessation in patients with coronary artery disease. Patient Educ Couns 1997;32:197-205.

29 Kerr S, Watson H, Tolson D, et al. Smoking after the age of 65 years: a qualitative exploration of older current and former smokers' views on smoking, stopping smoking, and smoking cessation resources and services. Health Soc Care Community 2006; 14:572-82.

30 Clark MA, Hogan JW, Kviz FJ, et al. Age and the role of symptomatology in readiness to quit smoking. Addict Behav 1999;24:1-16.

31 Snaterse M, Scholte Op Reimer WJM, Dobber J, et al. Smoking cessation after an acute coronary syndrome: immediate quitters are successful quitters. Neth Heart J 2015;23:600-7.

32 Celidoni M, Rebba V. Healthier lifestyles after retirement in Europe? Evidence from share. Eur J Health Econ 2017;18:805-30. 